Published in final edited form as:

Semin Cancer Biol. 2012 April ; 22(2): 166-172. doi:10.1016/j.semcancer.2011.12.001.

\title{
The role of miRNAs and EBV BARTs in NPC
}

\author{
Aron R. Marquitz ${ }^{a}$ and Nancy Raab-Trauba ${ }^{a, b, \S}$ \\ aLineberger Comprehensive Cancer Center, University of North Carolina at Chapel Hill, Chapel \\ Hill, North Carolina 27599 \\ bDepartment of Microbiology-Immunology, University of North Carolina at Chapel Hill, Chapel Hill, \\ North Carolina 27599
}

\begin{abstract}
The BamHI A Rightward Transcripts are a set of alternatively splicing transcripts produced by Epstein-Barr Virus that are highly expressed in nasopharyngeal carcinoma. These transcripts contain several open reading frames as well as precursors for twenty two miRNAs. Although the putative proteins corresponding to these open reading frames have not been detected, several studies have identified properties that are interesting and potentially significant with respect to cellular transformation. The miRNAs, however, are very abundant in all nasopharyngeal carcinomas and several potentially significant functions have been identified for some of the miRNAs. This article will focus on the nature of this complicated set of transcripts and the evidence that they contribute to the development of nasopharyngeal carcinoma.
\end{abstract}

\section{Keywords}

EBV; BARTs; miRNAs; NPC

\section{Introduction}

The Epstein-Barr Virus (EBV) is a ubiquitous member of the herpesvirus family that is considered an etiologic factor in the development of several human malignancies. A major malignancy is nasopharyngeal carcinoma (NPC) which occurs globally at a rate of 1 in 100,000 adults with highly elevated incidence of 20-50 per 100,000 in areas of southern China. The first evidence of an association of EBV infection with NPC was the identification of IgA antibodies to the EBV viral capsid antigen in NPC patient serum [1]. Subsequently EBV DNA was identified within the malignant epithelial cells of undifferentiated NPC regardless of geographic location while in Southern China, EBV is detected in all examples of NPC regardless of the differentiation subtype [2,3]. Furthermore, a clonal EBV infection was found in early, preinvasive lesions suggesting a role in initiation of NPC tumors [4]. The detection of the viral genome and viral proteins and RNAs in all cells within a tumor strongly suggest a causative role for EBV infection in NPC.

() 2011 Elsevier Ltd. All rights reserved.

Correspondence to: Aron R. Marquitz.

§Corresponding Author: NRT: nrt@med.unc.edu Phone: (919) 966-1701 Fax: (919) 966-9673. ARM: arm6@med.unc.edu.

Publisher's Disclaimer: This is a PDF file of an unedited manuscript that has been accepted for publication. As a service to our customers we are providing this early version of the manuscript. The manuscript will undergo copyediting, typesetting, and review of the resulting proof before it is published in its final citable form. Please note that during the production process errors may be discovered which could affect the content, and all legal disclaimers that apply to the journal pertain. 
In NPC, EBV expression is restricted to a subset of the latent transcripts that are expressed in EBV-transformed B-lymphocytes and in transplant-associated lymphoproliferative disorders. Of the six EBV latent nuclear antigens, only EBNA1 expression is detected in NPC tumor biopsies [5]. However, the latent membrane proteins LMP1 and LMP2A [5,6], as well as two highly abundant, small noncoding RNAs (EBERs) [7], are consistently expressed in NPC. In addition to these latent genes, BARF1, an early lytic protein in infected lymphocytes, has been detected in NPC [8,9]. Importantly, the BamHI A rightward transcripts (BARTs) are consistently and highly expressed in NPC [10]. The BARTs are an overlapping group of differentially spliced RNAs that are 3' coterminal and possibly initiate from two transcriptional start sites [11]. The complex differential splicing produces multiple open reading frames (ORFs) for proteins and precursors for microRNAs (miRNAs). The potential contribution of the BARTs in the pathogenesis of NPC is likely to be continuingly illuminating, however, this review will summarize our current understanding of the nature and function of the BARTs with particular emphasis on relationships to NPC.

\section{Identification and Structure of the BARTs}

\subsection{Initial Characterization and Expression Patterns of the BARTs}

The BARTs were first identified as abundant viral transcripts in cDNA libraries prepared from the C15 NPC tumor that is serially passaged in nude mice $[12,13,14]$ Northern blotting revealed a predominant band of $4.8 \mathrm{~kb}$ that was expressed in this tumor, although several other sized bands are also apparent [13,15]. Subsequent studies suggested that these transcripts were present in other NPC xenografts as well as in NPC biopsies [10]. These transcripts were striking in that they were highly abundant in NPC but had not been identified in EBV transformed lymphocytes. However they were antisense to the several known open reading frames encoding lytic proteins, including BALF5, the viral DNA polymerase [14]. It was suggested that the transcripts may contribute to the inhibition of replicative genes and were referred to as complementary strand transcripts (CSTs) [15].

Interestingly, this region was shown to be abundantly transcribed in early studies of viral transcription in NPC and Burkitt's lymphomas (BL) biopsies [16,17]. Although BART transcription can be detected using RT-PCR in all latently infected cell types, their relative abundance is highest in the more restricted Type 1 and Type 2 patterns of latency found in the tumors associated with EBV and low to undetectable in EBV transformed lymphocytes expressing the Type 3 full pattern of latent genes $[18,19]$. Interestingly, most of the DNA encoding the BART transcripts is deleted in the prototype B95-8 strain of EBV [20]. The B95-8 cell line was selected for high virus production and the virus produced from it is efficient in lymphocyte transformation. Additionally, a recombinant virus that is deleted for the entire region of the genome encoding the BARTs is still capable of infecting and transforming B lymphocytes in vitro [21]. These findings indicate that the BART transcripts are not required for B-lymphocyte transformation which is in agreement with the negligible levels of expression in Type 3 latency. However, the abundant expression of the BART transcripts in EBV associated tumors that do not express most of the potent EBNA proteins suggests that they are major contributors to tumor development or growth. It is also possible that the BARTs contribute to the maintenance of latency through antisense effects on the replicative genes on the opposite strand of the genome for the BARTs. Importantly, the highest expression of the BARTs is detected in infected epithelial cells, including NPC and gastric cancer, which may indicate that the BARTs have specific properties in epithelial cells. 


\subsection{Structure and splicing patterns of the BARTs}

The BARTs are a series of transcripts that share a common 3' terminus and are produced by a complicated series of alternative splicing. A variety of experimental techniques including sequencing DNA clones, RT-PCR, and RNase protection assays have been used to map the various forms of the transcripts that exist in NPC, as well as other EBV-associated tumors $[11,22,23,24]$. The general structure is one of seven exons (named I through VII), although significant variety exists at multiple locations (Figure 1). Exons III, V, and VII contain additional splicing sites that can result in excision of parts of those exons. Exons II and VI are not always included in the final transcript and there are an additional two exons (Ia and Ib) that are sometimes included between exons I and II.

There is no large ORF that spans the length of any of the identified BARTs, however, there are several smaller ORFs that may encode for proteins. All of the transcripts contain exon VII, which has a small ORF indicated by blue in Figure 1, that could potentially encode a 174 amino acid protein termed BamHI A rightward frame 0 (BARF0) [10]. This ORF is particularly unusual in that the stop codon is embedded within a repeated polyadenylation signal such that only a subset of the transcripts would encompass the stop codon. A subset of these transcripts that contain alternative splicing in exon $\mathrm{V}$ and are directly spliced into the BARF0 ORF in exon VII, which would produce a larger version of this protein (279 amino acids) that has been referred to as RK-BARF0 [11]. An ORF, indicated in green, that spans exons IV and V would encode for a 103 aa protein, which has been called RPMS1 or RK103 [24]. Perhaps most interestingly, a consistent splice pattern that spans exons V, VI, and a distinct spliced form of exon VII results in an ORF indicated in yellow that is named A73 or RB2, which would produce a 126 aa protein [23]. Evidence for and against the production of the proteins from these ORFs will be reviewed in section 3.

\subsection{The BART promoter and regulation of expression}

Through sequencing of cDNA clones and 5'RACE the major transcriptional initiation site (P1) for the BARTs has been mapped to nucleotide 138357 of the wild type EBV sequence $[11,24,25]$. An alternative start site (P2) upstream from this has also been identified at position 138067 [25]. These two transcriptional start sites appear to be under differential regulation. The P1 site can be stimulated by binding of Jun family members to the consensus AP-1 site directly upstream and can be suppressed by binding of IRF family members to an IRF site [25]. The P2 site can be stimulated by c-myc and C/EBP family members and there are potential myc and C/EBP binding sites directly upstream of P2 [25]. C/EBP family members may be of significant interest since they are highly expressed in cells of epithelial origin, thus, it has been hypothesized that upregulation of the transcription from the $\mathrm{P} 2$ site may be responsible for the high levels of BARTs seen in NPC and other epithelial cells [25].

Many EBV latent promoters are regulated by methylation of $\mathrm{CpG}$ dinucleotides, with decreased levels of methylation corresponding with increased levels of transcription [26]. In NPC tumors and cell lines, the promoter region of the BARTs has been shown to be hypomethylated compared to the rest of the genome, consistent with high levels of expression [27,28]. Also, a recent report demonstrated that treatment of EBV-infected B lymphocytes with a DNA methyltransferase inhibitor led to an induction of the BARTs, consistent with a role of DNA methylation in regulating the BART promoter [29].

\section{Potential BART-encoded proteins}

Several open reading frames exist within the BARTs that have the potential to produce proteins with interesting functions with respect to the development of NPC. However, whether these proteins are actually translated in vivo remains a point of controversy. Evidence for and against the relevance of these ORFs is presented below. 


\subsection{BARF0 and RK-BARF0}

All BARTs share the same 3' end, and, therefore, share an ORF named BARF0, which is located in the last exon of each transcript [10]. However, differential splicing can produce an $\mathrm{N}$-terminal extension of this ORF named RK-BARF0 [11]. In both of these ORFs, there is a canonical poly-A addition sequence that occurs just upstream of the stop codon and 3'RACE of these transcripts revealed that a majority terminate before the stop codon [11]. This calls into question whether this ORF is actually translated to produce a protein in infected cells.

Currently, the experiments designed to determine whether the BARF0 or RK-BARF0 gene products are actually made have been inconclusive. In vitro translated BARF0 could be immunoprecipitated using serum from NPC patients suggesting these patients produced antibodies directed against the protein [10]. In addition, cytotoxic $\mathrm{T}$ lymphocytes from EBV-seropositive patients, but not -seronegative, exhibited a response when stimulated with a BARF0 peptide [30]. However, a BL cell line expressing recombinant BARF0 did not elicit a similar response [30]. A rabbit antibody generated to a peptide in BARF0 that bound the exogenous BARF0 and RK-BARF0 on Western blots revealed evidence of 30 and $35 \mathrm{kD}$ proteins in many EBV-infected cell types [31]; however, these bands were also seen in some EBV negative cell lines, suggesting a lack of specificity for this antibody [32] and subsequent analysis revealed that this antibody also bound to HLA-DR $\beta$ chain [33]. Affinity purification of this antibody removed this cross reactivity, but the affinity-purified antibody could not consistently detect BARF0 protein in EBV-infected cells by Western blotting [34].

Despite a lack of an ability to clearly demonstrate production of protein directly from the BARTs, exogenous BARF0 and RK-BARF0 do have interesting biological properties. Through both immunofluorescence of FLAG-tagged constructs and direct imaging of GFPtagged constructs, BARF0 and RK-BARF0 localized to the nucleus of transfected HeLa or BL cell lines [32]. In addition, RK-BARF0 has been shown to interact with Notch family members by yeast two-hybrid as well as immunoprecipitation [35]. Expression of RKBARF0 sequesters Notch in the nucleus, as well as promotes its proteasome-mediated degradation, preventing its normal maturation and expression as a cell surface receptor and, thus, also preventing its interaction with RBP-JK/CBF1 $[34,35]$. This is a potentially interesting interaction given that the EBV latent protein EBNA2 requires binding RBP-J $\mathrm{K}$ to activate transcription of genes such as the EBV oncoprotein LMP1 [36,37,38], and in fact, expression of RK-BARF0 leads to an increased level of LMP1 [35].

\subsection{RPMS1}

The most proximal potential ORF in the BARTs spans the junction between exons IV and V and would code for an 103 aa protein that has been termed RPMS1 (also known as RK103) $[11,24]$. Given that the most abundant BARTs contain both RPMS1 and BARF0 on the same transcript [23], a reasonable prediction would be translation of RPMS1 would be favored as the proximal transcript on the message. However, detection of native RPMS1 has also not been possible in EBV cell lines and tumors, despite the production of two monoclonal antibodies that recognize the recombinant protein by immunofluorescence and Western blotting [27].

However, similar to BARF0, RPMS1 also has interesting biological properties when produced exogenously in cell lines. Overexpression of RPMS1 in HEK293 cells resulted in increased growth in soft agar and cells that can form tumors in nude mice [39]. Flag-tagged RPMS1 localized to the nucleus in both 293T and HeLa cells [23,40]. RPMS1 has been shown through a variety of assays to bind to RBP-J $/$ /CBF1 as well as with members of a repressive histone deacetylase complex that interacts with RBP-J $\times$ [23,41]. This interaction 
has been shown to be able to inhibit RBP-J $x$-dependent Notch or EBNA2 gene activation $[23,41]$. It is interesting that two potential proteins produced by the BARTs have the ability to downregulate Notch signaling, suggesting that this pathway might be of particular interest in EBV biology. Depending on context, Notch signaling can have both an oncogenic or tumor suppressive phenotype [42], thus, it is not clear at this point how affecting this pathway might contribute to NPC development.

\subsection{A73}

Alternative splicing within exon VII can produce an additional ORF that spans exons V, VI, and VII that would code for a 126 aa protein that has been named A73, also known as RB2 $[11,23]$. As with the other potential BART proteins, monoclonal antibodies have been unable to identify the native protein for this ORF in either EBV-infected cell lines or tumors [27]. Unlike BARF0 and RPMS1, exogenously expressed A73 is a cytoplasmic protein. A yeast two-hybrid screen identified interactions with both RACK1 (receptor for activated C kinase 1) and $\beta 5$-integrin [23]. RACK1 has been shown to regulate release of calcium ions from intracellular stores and expression of A73 in 293 cells resulted in an increase of UTP stimulated calcium release [27]. At this time it is unclear if this or another function of A73 might play a role in the development of NPC.

\section{BART-encoded miRNAs}

Perhaps the biggest finding with respect to the function of the BARTs was made when the first viral miRNAs were cloned from an EBV-infected B cell line. Five miRNAs were identified as being derived from the EBV genome, including two from the introns of the BARTs [43]. Three of the miRNAs were located near the BHRF1 ORF that encodes a bcl2 homologue. These miRNAs have subsequently been shown to only be present in cells in Type 3 latency that express the primary EBNA transcript that initiates from the Wp or Cp promoters [44]. miRNAs are approximately 22 nucleotide RNAs processed from hairpin structures of larger RNA that function in protein repression through a mechanism that is similar to siRNAs [45]. As the putative protein products for the BART ORFs have not been identified, the finding that the BARTs could serve as a template for miRNAs was a major discovery. This initial study used cells infected with the B95-8 laboratory isolate, an unusual strain of EBV that has a $12 \mathrm{~kb}$ deletion that spans many of the 5' noncoding exons of the BARTs [20]. Subsequent studies using cell lines infected with undeleted EBV as well as the use of high throughput sequencing methods, have demonstrated that the BARTs encode for 22 miRNA precursors and because each miRNA hairpin can in principle code for two miRNAs (one from each arm), as many as 44 mature BART miRNAs can be found in EBVinfected cells $[44,46,47,48]$.

\subsection{BART miRNA nomenclature and expression patterns}

The BART miRNAs have been named ebv-mir-BART1-22 with the numbers corresponding to the order in which they were original discovered. In typical miRNA biogenesis, one strand of the miRNA hairpin is selected to be the mature miRNA, while the other strand is quickly degraded [45]. However, this is not always the case and in some instances, including rather frequently for the BART miRNAs, both strands of the original hairpin persist and can, therefore, be functionally relevant. To distinguish between the two potential miRNAs that can be produced by each hairpin the suffixes $-5 p$ and $-3 p$ have been used to designate the 5 , end of the hairpin and 3' end of the hairpin for cases in which there appears to be significant mature miRNAs produced from each hairpin. In cases where one side of the hairpin is dramatically favored over the other in terms of abundance, the less abundant miRNA is designated with a $*$, consistent with the nomenclature used for all miRNAs, when referring to the opposite, less abundant strand miRNA [45]. A complete listing of the EBV miRNAs 
with both mature and precursor sequences, as well as accepted nomenclature can be found at www.mirbase.org.

A significant amount of effort has been made to determine the expression patterns of the BART miRNAs. This is of interest primarily because the effectiveness of any particular miRNA is necessarily tied to its abundance, as miRNA function is a process dependent upon stoichiometric relationship of miRNA to target mRNA. While it is clear that in general the BART miRNAs are expressed higher in cell lines and tumors in which the BARTs themselves are expressed higher [44], it is also true that the concentrations of each of the individual miRNAs vary by several orders of magnitude from each other.

Two methods have been used to determine the abundance of BART miRNAs in NPC tumors and cell lines. The first is a step loop PCR method used to perform RT PCR from very small RNA templates such as miRNAs [49]. This method has been used to profile the expression levels of the BART miRNAs from both the NPC derived cell line, C666-1, as well as directly from NPC biopsy samples [50,51,52,53]. In addition, relative abundance can be determined by the relative representation in directly sequenced small RNA libraries; and several groups have used both traditional and high throughput methods to sequence miRNAs from NPC cell lines, xenografts, and biopsies [47,48,54]. Estimations can be made from both of these methods with regards to copies of miRNA/cell; either from miRNA abundance in a standard amount of total RNA in the case of PCR, or from the percentage abundance of a particular miRNA with respect to the total pool in the case of sequencing. Both approaches have determined that the individual BART miRNAs vary greatly in abundance in NPC, with the most abundant being present at concentrations in the thousands of copies per cell and the least abundant being expressed at a few copies per cell or less (Figure 2). Comparison of these studies indicates that while some miRNAs appear to be consistently abundant in NPC and others are hardly expressed at all, there is a significant percentage of the BART miRNAs that vary greatly across studies. This variation appears to be due to more than just differences in the samples used, as the profile of the relative abundance of miRNAs present in the C666-1 cell line varies considerably. For example, the relative abundance of miRBART15 as determined by PCR differs considerably among three studies and is different if determined by sequencing [50,51,54]. Strikingly one of the highest expressing miRNAs in C666 cells by sequencing, miR-BART10 [54], only showed modest expression in the same cells by RT-PCR [51]; whereas miR-BART19-3p, which appeared to be highly abundant in PCR studies of cells or tumors [51,53], only appeared at low levels or was not detected at all in sequencing studies $[47,48,54]$. In some instances, different studies yield opposite results with respect to which strand of a miRNA is the dominant form. For example, in the two PCR studies that have examined both miR-BART2-5p and $-3 p$, one found the $-5 p$ version to be several order of magnitude higher in abundance while the other study found the opposite [51,53]; despite this neither appears in very high abundance in the sequencing studies $[47,48,54]$. It is true that each method of estimating miRNA abundance comes with its own caveats. The step loop PCR method relies on precise knowledge to the 3' end of the miRNA, which in the case of the BARTs has been shown to be variable throughout the population [48]. Additionally, sequence-specific biases are also introduced by the RNA ligation step used to generate small RNA libraries for sequencing [55].

The reason for the apparent differences in abundance of the individual BART miRNA within a single infected cell is not known. Theoretically, such differences in steady state levels could be due to differences in stability, differences in precursor transcription, or differences in the processing to produce the mature miRNA. Relative stability of the various BART miRNAs has not been evaluated to this date, so the extent to which that plays a role in steady state abundance is not clear. It would seem unlikely that differential rates of transcription could account for the different relative abundances as the miRNAs are tightly 
clustered in the BART introns, and should in theory all be transcribed together. The differential splicing that occurs in the transcripts could possibly account for some of the differences if specific splicing events favor or inhibit the excision of the miRNA hairpins based on their location. In support of this possibility cell lines that accumulate higher levels of the BART miRNAs also favor a version of the BART mRNA in which exon I is spliced directly to exon III [22]. This is true despite the fact that the miRNAs appear to be processed out of the initial transcript prior to completion of the splicing reaction, as stable RNAs resulting from miRNA excision span the exon/intron boundaries [22]. It is presently unknown whether the final spliced mRNAs are a product of splicing that occurs after the excision of the miRNAs or they are made from a pool of transcripts that are distinct from those that are the template for miRNA production. Further experimentation into the role splicing plays in the production of the miRNAs will be necessary to clarify this issue. Another possibility to explain the different levels of the BART miRNAs would be if each miRNA is recognized with a different affinity for the enzyme responsible for the excision of the hairpin, the Drosha/DGCR8 microprocessor complex [56]. This is another hypothesis that has not been fully explored, but it is worth noting that the stable BART RNA fragments that can be isolated from nuclei of EBV infected cell lines often have particular miRNAs excised, while others have not been processed out, suggesting there is some order or bias to the processing by the microprocessor complex [22].

\subsection{Viral targets for BART miRNAs}

In order to fully understand the potential role for the BART miRNAs in the development of NPC, it is necessary to determine the targets of the miRNA-mediated downregulation. In principle the targets could be other viral transcripts or transcripts from the host cell. Targeting viral transcripts may be an important way to maintain latency by targeting of lytic transcripts or to avoid immune detection through maintaining low levels of other latent gene products. Perhaps the most straightforward function for a BART miRNA is in the case of miR-BART2. miR-BART2 is located apart from the two clusters of miRNAs further upstream and is directly antisense to the 3'UTR of BALF5, the viral DNA polymerase [43]. Given the obvious perfect complementarity of miR-BART2 to the BALF5 transcript, it is not surprising that expression of the miRNA was shown to downregulate BALF5 protein expression, through a mechanism that involves cleavage of the BALF5 mRNA at the site of miR-BART2 binding [57]. There is also evidence that other BART miRNAs can regulate the latent transcripts of EBV that are expressed in NPC. Several BART miRNAs from cluster I have been shown to be able to target the 3'UTR of LMP1 and result in downregulation of the protein [58]. In addition, a cluster II miRNA, miR-BART22, has been shown to downregulate LMP2 at the protein level [54]. In all of these cases, the consequences of miRNA action for the viral life cycle or for cancer progression have not been fully explored. It will be interesting to determine whether any of these potential functions for BART miRNAs contribute to EBV oncogenesis in vivo.

\subsection{Cellular targets for BART miRNAs}

For a majority of the BART miRNAs, a clear viral transcript target is not apparent. The most likely function of these miRNAs would be downregulating transcripts from the host cell. In the past few years, some progress has been made in identifying such targets. Excitingly, many of the targets identified at this point have roles as tumor suppressors, further highlighting the potential important role the BART miRNAs may play in the development of NPC.

Several of the cellular targets identified to this date have roles in promoting apoptosis and, thus, the miRNAs that target them have anti-apoptotic affects. miR-BART5 was predicted to target the $\mathrm{BH}$-only protein PUMA, which helps mediate cytochrome c release from the 
mitochondria in response to apoptotic stimuli, through complementarity with the 3'UTR of the PUMA mRNA [59]. Downregulation of PUMA by miR-BART5 was confirmed using 3'UTR reporter assays as well as Western blots . Another BH3-only protein, Bim, was identified by microarray analysis looking for transcripts that decreased in abundance in cells expressing the BART miRNAs [60]. Bim was also been shown to be targeted by multiple BART miRNAs from cluster I through reporter assays and Western blots. Interestingly, Bim is a tumor suppressor that is targeted by a number of oncogenic cellular miRNAs in other forms of cancer $[61,62,63]$. In addition, in a study looking for EBV miRNA targets by immunoprecipitating the RNA-induced silencing complex (RISC), TOMM22 was identified as a potential target for miR-BART16 [64]. TOMM22 is a part of a mitochondrial pore complex that serves as a receptor for the proapoptotic protein Bax; knockdown of TOMM22 by siRNA has been shown to be anti-apoptotic [65]. Targeting of TOMM22 was confirmed by the 3'UTR reporter assay, although direct regulation of protein levels was not assessed [64].

In addition to genes involved in apoptosis, other tumor suppressor genes have also been implicated as targets for the BART miRNAs. Multiple tumor suppressors that target the Wnt signaling pathway were shown to be downregulated by Western blots in cells expressing the appropriate miRNAs, including WIF1 (miR-BART19-3p) and APC (miR-BART7, 19-3p, and 17-5p) [53]. Other targets for BART miRNAs have also been identified in which the role in NPC would be less clear including IPO7 for miR-BART3 [64], Dicer for miRBART6-5p [66], and MICB for miR-BART2-5p [67]. As each individual miRNA could target multiple genes and pathways at the same time, it is likely that many more cellular targets will be affected by the BART miRNAs.

\subsection{BART miRNAs in the serum}

In addition to being functionally relevant in the tumor cells they are produced in, tumorassociated miRNAs can also be secreted from cells and are present in high copies in the serum $[68,69,70]$. This is also true of the BART miRNAs, which are present in high concentrations in the serum of NPC patients [53,71]. It is possible that the detection of BART miRNAs in the serum of NPC patients might be used as a biomarker as tumor specific cellular RNAs have proven to be useful in other types of cancer [72]. Given that miRNAs in the serum are in a cell-free compartment that is highly stable and resistant to RNAse [70], and the fact that miRNAs have been shown to be secreted from cells in small vesicles known as exosomes [73], the current hypothesis is that most if not all of serum miRNAs are contained within exosomes. The BART miRNAs have been shown to be packaged into exosomes from both NPC xenografts and cell lines[71,74]. Interestingly, the BART miRNAs can be transferred to recipient uninfected cells, and the transferred miRNAs remain functional in downregulating protein expression [74,75]. This opens up the possibility that the BART miRNAs may affect not only the EBV-infected cells of a tumor, but the surrounding uninfected cells as well.

\section{Conclusions and Future Directions}

The EBV BARTs are a highly expressed and complicated set of transcripts that encode for a large number of miRNAs, as well as potentially interesting proteins in NPC. Considering the high levels of BART miRNAs that are detected in clinical samples and the lack of evidence of BART protein production, it seems likely that the major role for these transcripts is the production of miRNAs. It is not clear, however, if there is a situation in which the ORFs are also translated. It is presently unknown whether one transcript can be processed for miRNA production and also translated. A study of the BHRF1 miRNA production and effects on BHRF1 mRNA and protein synthesis indicated that Drosha inhibition did not affect the abundance or stability of the unspliced BHRF1 mRNA and suggested that the mRNAs might 
be produced from a distinct template [76]. It would be interesting to know if inhibiting miRNA production by knocking down Drosha for example would enable translation of the downstream ORFs. There appears to be a correlation between different splicing patterns and the amount of miRNAs produced, which leads to the interesting hypothesis that production of the miRNAs may influence the structure of the transcripts themselves and perhaps then even the translation of potential ORFs. It could also be that forcing different splicing patterns would result in a different balance of miRNAs/proteins produced as end products. A better understanding of the mechanisms regulating the maturation of the BARTs might identify factors that favor protein production over miRNA generation.

Many of the potential cellular gene products targeted by the BART miRNAs have important functions and several possibly modulate apoptosis. The determination of whether the BART miRNAs are necessary or sufficient for the growth properties characteristic of NPC will be difficult. In addition to the difficulty in transforming epithelial cells by EBV infection, the large number of BART miRNAs suggests the possibility that they may work in concert. Thus, standard antisense inhibition experiments to determine if they are required for growth or maintenance of tumors will be daunting. The identification of the expression patterns and the functional capabilities of each individual miRNA will help in selecting candidate miRNAs that possibly function as oncomirs. Despite the considerable effort in profiling BART miRNA abundance, there are still large disparities in the various data sets. While some of these disparities may be due to various biases in the techniques used, it is probably also true that there are more complexities that have yet to be considered. For example, the stability of each miRNA is completely unknown at this point, as is what factors might affect that stability.

Considering the highly restricted patterns of viral protein expression in most of the tumors associated with EBV, the abundance of the BART miRNAs suggests that they are likely to be a major factor in the contribution of EBV to oncogenesis and in particular to NPC. Although the overall biologic effects of these miRNAs are presently unknown, it is likely that BART miRNA directed therapies will be developed as their molecular properties are experimentally defined and their potential contribution to the pathogenesis of NPC is clarified.

\section{Acknowledgments}

Research focused on the BART miRNAs in the N.R.T. lab was supported by grant CA138811 from the National Institutes of Health to N.R.T. A.R.M. has been supported by fellowship 5059-08 from the Leukemia and Lymphoma Society.

\section{References}

1. Henle G, Henle W. Epstein-Barr virus-specific IgA serum antibodies as an outstanding feature of nasopharyngeal carcinoma. Int J Cancer. 1976; 17:1-7. [PubMed: 175020]

2. Raab-Traub N, Flynn K, Pearson G, Huang A, Levine P, Lanier A, et al. The differentiated form of nasopharyngeal carcinoma contains Epstein-Barr virus DNA. Int J Cancer. 1987; 39:25-9. [PubMed: 3025109]

3. Wolf H, Zur Hausen H, Klein G, Becker V, Henle G, Henle W. Attempts to detect virus-specific DNA sequences in human tumors. III. Epstein-Barr viral DNA in non-lymphoid nasopharyngeal carcinoma cells. Med Microbiol Immunol. 1975; 161:15-21. [PubMed: 165392]

4. Pathmanathan R, Prasad U, Sadler R, Flynn K, Raab-Traub N. Clonal proliferations of cells infected with Epstein-Barr virus in preinvasive lesions related to nasopharyngeal carcinoma. N Engl J Med. 1995; 333:693-8. [PubMed: 7637746]

5. Young LS, Dawson CW, Clark D, Rupani H, Busson P, Tursz T, et al. Epstein-Barr virus gene expression in nasopharyngeal carcinoma. J Gen Virol. 1988; 69(Pt 5):1051-65. [PubMed: 2836550] 
6. Busson P, McCoy R, Sadler R, Gilligan K, Tursz T, Raab-Traub N. Consistent transcription of the Epstein-Barr virus LMP2 gene in nasopharyngeal carcinoma. J Virol. 1992; 66:3257-62. [PubMed: 1313931]

7. Sam CK, Brooks LA, Niedobitek G, Young LS, Prasad U, Rickinson AB. Analysis of Epstein-Barr virus infection in nasopharyngeal biopsies from a group at high risk of nasopharyngeal carcinoma. Int J Cancer. 1993; 53:957-62. [PubMed: 8386141]

8. Decaussin G, Sbih-Lammali F, de Turenne-Tessier M, Bouguermouh A, Ooka T. Expression of BARF1 gene encoded by Epstein-Barr virus in nasopharyngeal carcinoma biopsies. Cancer Res. 2000; 60:5584-8. [PubMed: 11034107]

9. Seto E, Yang L, Middeldorp J, Sheen TS, Chen JY, Fukayama M, et al. Epstein-Barr virus (EBV)encoded BARF1 gene is expressed in nasopharyngeal carcinoma and EBV-associated gastric carcinoma tissues in the absence of lytic gene expression. J Med Virol. 2005; 76:82-8. [PubMed: 15778977]

10. Gilligan KJ, Rajadurai P, Lin JC, Busson P, Abdel-Hamid M, Prasad U, et al. Expression of the Epstein-Barr virus BamHI A fragment in nasopharyngeal carcinoma: evidence for a viral protein expressed in vivo. J Virol. 1991; 65:6252-9. [PubMed: 1656092]

11. Sadler RH, Raab-Traub N. Structural analyses of the Epstein-Barr virus BamHI A transcripts. J Virol. 1995; 69:1132-41. [PubMed: 7815492]

12. Busson P, Ganem G, Flores P, Mugneret F, Clausse B, Caillou B, et al. Establishment and characterization of three transplantable EBV-containing nasopharyngeal carcinomas. Int J Cancer. 1988; 42:599-606. [PubMed: 2971626]

13. Gilligan K, Sato H, Rajadurai P, Busson P, Young L, Rickinson A, et al. Novel transcription from the Epstein-Barr virus terminal EcoRI fragment, DIJhet, in a nasopharyngeal carcinoma. J Virol. 1990; 64:4948-56. [PubMed: 2168978]

14. Hitt MM, Allday MJ, Hara T, Karran L, Jones MD, Busson P, et al. EBV gene expression in an NPC-related tumour. Embo J. 1989; 8:2639-51. [PubMed: 2479554]

15. Karran L, Gao Y, Smith PR, Griffin BE. Expression of a family of complementary-strand transcripts in Epstein-Barr virus-infected cells. Proc Natl Acad Sci U S A. 1992; 89:8058-62. [PubMed: 1325642]

16. Dambaugh T, Nkrumah FK, Biggar RJ, Kieff E. Epstein-Barr virus RNA in Burkitt tumor tissue. Cell. 1979; 16:313-22. [PubMed: 222455]

17. Raab-Traub N, Hood R, Yang CS, Henry B 2nd, Pagano JS. Epstein-Barr virus transcription in nasopharyngeal carcinoma. J Virol. 1983; 48:580-90. [PubMed: 6313960]

18. Brooks LA, Lear AL, Young LS, Rickinson AB. Transcripts from the Epstein-Barr virus BamHI A fragment are detectable in all three forms of virus latency. J Virol. 1993; 67:3182-90. [PubMed: 8388496]

19. Sugiura M, Imai S, Tokunaga M, Koizumi S, Uchizawa M, Okamoto K, et al. Transcriptional analysis of Epstein-Barr virus gene expression in EBV-positive gastric carcinoma: unique viral latency in the tumour cells. Br J Cancer. 1996; 74:625-31. [PubMed: 8761381]

20. Raab-Traub N, Dambaugh T, Kieff E. DNA of Epstein-Barr virus VIII: B95-8, the previous prototype, is an unusual deletion derivative. Cell. 1980; 22:257-67. [PubMed: 6253079]

21. Robertson ES, Tomkinson B, Kieff E. An Epstein-Barr virus with a 58-kilobase-pair deletion that includes BARF0 transforms B lymphocytes in vitro. J Virol. 1994; 68:1449-58. [PubMed: 8107208]

22. Edwards RH, Marquitz AR, Raab-Traub N. Epstein-Barr virus BART microRNAs are produced from a large intron prior to splicing. J Virol. 2008; 82:9094-106. [PubMed: 18614630]

23. Smith PR, de Jesus O, Turner D, Hollyoake M, Karstegl CE, Griffin BE, et al. Structure and coding content of CST (BART) family RNAs of Epstein-Barr virus. J Virol. 2000; 74:3082-92. [PubMed: 10708423]

24. Smith PR, Gao Y, Karran L, Jones MD, Snudden D, Griffin BE. Complex nature of the major viral polyadenylated transcripts in Epstein-Barr virus-associated tumors. J Virol. 1993; 67:3217-25. [PubMed: 8098777] 
25. Chen H, Huang J, Wu FY, Liao G, Hutt-Fletcher L, Hayward SD. Regulation of expression of the Epstein-Barr virus BamHI-A rightward transcripts. J Virol. 2005; 79:1724-33. [PubMed: 15650197]

26. Salamon D, Takacs M, Ujvari D, Uhlig J, Wolf H, Minarovits J, et al. Protein-DNA binding and CpG methylation at nucleotide resolution of latency-associated promoters Qp, Cp, and LMP1p of Epstein-Barr virus. J Virol. 2001; 75:2584-96. [PubMed: 11222681]

27. Al-Mozaini M, Bodelon G, Karstegl CE, Jin B, Al-Ahdal M, Farrell PJ. Epstein-Barr virus BART gene expression. J Gen Virol. 2009; 90:307-16. [PubMed: 19141439]

28. de Jesus O, Smith PR, Spender LC, Elgueta Karstegl C, Niller HH, Huang D, et al. Updated Epstein-Barr virus (EBV) DNA sequence and analysis of a promoter for the BART (CST, BARF0) RNAs of EBV. J Gen Virol. 2003; 84:1443-50. [PubMed: 12771413]

29. Kim DN, Song YJ, Lee SK. The Role of Promoter Methylation in Epstein-Barr Virus MicroRNA Expression in EBV-infected B cell lines. Exp Mol Med. 2011

30. Kienzle N, Sculley TB, Poulsen L, Buck M, Cross S, Raab-Traub N, et al. Identification of a cytotoxic T-lymphocyte response to the novel BARF0 protein of Epstein-Barr virus: a critical role for antigen expression. J Virol. 1998; 72:6614-20. [PubMed: 9658107]

31. Fries KL, Sculley TB, Webster-Cyriaque J, Rajadurai P, Sadler RH, Raab-Traub N. Identification of a novel protein encoded by the BamHI A region of the Epstein-Barr virus. J Virol. 1997; 71:2765-71. [PubMed: 9060630]

32. Kienzle N, Buck M, Greco S, Krauer K, Sculley TB. Epstein-Barr virus-encoded RK-BARF0 protein expression. J Virol. 1999; 73:8902-6. [PubMed: 10482651]

33. Schroder W, Kienzle N, Bushell G, Sculley T. Antiserum raised against the Epstein-Barr virus BARF0 protein reacts to HLA-DR beta chain. Arch Virol. 2002; 147:723-9. [PubMed: 12038683]

34. Thornburg NJ, Kusano S, Raab-Traub N. Identification of Epstein-Barr virus RK-BARF0interacting proteins and characterization of expression pattern. J Virol. 2004; 78:12848-56. [PubMed: 15542637]

35. Kusano S, Raab-Traub N. An Epstein-Barr virus protein interacts with Notch. J Virol. 2001; 75:384-95. [PubMed: 11119607]

36. Grossman SR, Johannsen E, Tong X, Yalamanchili R, Kieff E. The Epstein-Barr virus nuclear antigen 2 transactivator is directed to response elements by the $\mathrm{J}$ kappa recombination signal binding protein. Proc Natl Acad Sci U S A. 1994; 91:7568-72. [PubMed: 8052621]

37. Henkel T, Ling PD, Hayward SD, Peterson MG. Mediation of Epstein-Barr virus EBNA2 transactivation by recombination signal-binding protein J kappa. Science. 1994; 265:92-5. [PubMed: 8016657]

38. Hofelmayr H, Strobl LJ, Stein C, Laux G, Marschall G, Bornkamm GW, et al. Activated mouse Notch1 transactivates Epstein-Barr virus nuclear antigen 2-regulated viral promoters. J Virol. 1999; 73:2770-80. [PubMed: 10074124]

39. Li A, Zhang XS, Jiang JH, Wang HH, Liu XQ, Pan ZG, et al. Transcriptional expression of RPMS1 in nasopharyngeal carcinoma and its oncogenic potential. Cell Cycle. 2005; 4:304-9. [PubMed: 15725729]

40. Chen H, Smith P, Ambinder RF, Hayward SD. Expression of Epstein-Barr virus BamHI-A rightward transcripts in latently infected B cells from peripheral blood. Blood. 1999; 93:3026-32. [PubMed: 10216099]

41. Zhang J, Chen H, Weinmaster G, Hayward SD. Epstein-Barr virus BamHi-a rightward transcriptencoded RPMS protein interacts with the CBF1-associated corepressor CIR to negatively regulate the activity of EBNA2 and NotchIC. J Virol. 2001; 75:2946-56. [PubMed: 11222720]

42. Ranganathan P, Weaver KL, Capobianco AJ. Notch signalling in solid tumours: a little bit of everything but not all the time. Nat Rev Cancer. 11:338-51. [PubMed: 21508972]

43. Pfeffer S, Zavolan M, Grasser FA, Chien M, Russo JJ, Ju J, et al. Identification of virus-encoded microRNAs. Science. 2004; 304:734-6. [PubMed: 15118162]

44. Cai X, Schafer A, Lu S, Bilello JP, Desrosiers RC, Edwards R, et al. Epstein-Barr virus microRNAs are evolutionarily conserved and differentially expressed. PLoS Pathog. 2006; 2:e23. [PubMed: 16557291] 
45. Bartel DP. MicroRNAs: genomics, biogenesis, mechanism, and function. Cell. 2004; 116:281-97. [PubMed: 14744438]

46. Grundhoff A, Sullivan CS, Ganem D. A combined computational and microarray-based approach identifies novel microRNAs encoded by human gamma-herpesviruses. Rna. 2006; 12:733-50. [PubMed: 16540699]

47. Zhu JY, Pfuhl T, Motsch N, Barth S, Nicholls J, Grasser F, et al. Identification of novel EpsteinBarr virus microRNA genes from nasopharyngeal carcinomas. J Virol. 2009; 83:3333-41. [PubMed: 19144710]

48. Chen SJ, Chen GH, Chen YH, Liu CY, Chang KP, Chang YS, et al. Characterization of EpsteinBarr virus miRNAome in nasopharyngeal carcinoma by deep sequencing. PLoS One. 2010; 5:e12745. [PubMed: 20862214]

49. Chen C, Ridzon DA, Broomer AJ, Zhou Z, Lee DH, Nguyen JT, et al. Real-time quantification of microRNAs by stem-loop RT-PCR. Nucleic Acids Res. 2005; 33:e179. [PubMed: 16314309]

50. Amoroso R, Fitzsimmons L, Thomas WA, Kelly GL, Rowe M, Bell AI. Quantitative studies of Epstein-Barr virus-encoded miRNAs provide novel insights into their regulation. J Virol. 2011; 85:996-1010. [PubMed: 21068248]

51. Cosmopoulos K, Pegtel M, Hawkins J, Moffett H, Novina C, Middeldorp J, et al. Comprehensive profiling of Epstein-Barr virus microRNAs in nasopharyngeal carcinoma. J Virol. 2009; 83:235767. [PubMed: 19091858]

52. Pratt ZL, Kuzembayeva M, Sengupta S, Sugden B. The microRNAs of Epstein-Barr Virus are expressed at dramatically differing levels among cell lines. Virology. 2009; 386:387-97. [PubMed: 19217135]

53. Wong AM, Kong KL, Tsang JW, Kwong DL, Guan XY. Profiling of Epstein-Barr virus-encoded microRNAs in nasopharyngeal carcinoma reveals potential biomarkers and oncomirs. Cancer. 2011

54. Lung RW, Tong JH, Sung YM, Leung PS, Ng DC, Chau SL, et al. Modulation of LMP2A expression by a newly identified Epstein-Barr virus-encoded microRNA miR-BART22. Neoplasia. 2009; 11:1174-84. [PubMed: 19881953]

55. Hafner M, Renwick N, Brown M, Mihailovic A, Holoch D, Lin C, et al. RNA-ligase-dependent biases in miRNA representation in deep-sequenced small RNA cDNA libraries. Rna. 2011; 17

56. Denli AM, Tops BB, Plasterk RH, Ketting RF, Hannon GJ. Processing of primary microRNAs by the Microprocessor complex. Nature. 2004; 432:231-5. [PubMed: 15531879]

57. Barth S, Pfuhl T, Mamiani A, Ehses C, Roemer K, Kremmer E, et al. Epstein-Barr virus-encoded microRNA miR-BART2 down-regulates the viral DNA polymerase BALF5. Nucleic Acids Res. 2008; 36:666-75. [PubMed: 18073197]

58. Lo AK, To KF, Lo KW, Lung RW, Hui JW, Liao G, et al. Modulation of LMP1 protein expression by EBV-encoded microRNAs. Proc Natl Acad Sci U S A. 2007; 104:16164-9. [PubMed: 17911266]

59. Choy EY, Siu KL, Kok KH, Lung RW, Tsang CM, To KF, et al. An Epstein-Barr virus-encoded microRNA targets PUMA to promote host cell survival. J Exp Med. 2008; 205:2551-60. [PubMed: 18838543]

60. Marquitz AR, Mathur A, Nam CS, Raab-Traub N. The Epstein-Barr Virus BART microRNAs target the proapoptotic protein Bim. Virology. 2011; 412:392-400. [PubMed: 21333317]

61. Petrocca F, Visone R, Onelli MR, Shah MH, Nicoloso MS, de Martino I, et al. E2F1-regulated microRNAs impair TGFbeta-dependent cell-cycle arrest and apoptosis in gastric cancer. Cancer Cell. 2008; 13:272-86. [PubMed: 18328430]

62. Terasawa K, Ichimura A, Sato F, Shimizu K, Tsujimoto G. Sustained activation of ERK1/2 by NGF induces microRNA-221 and 222 in PC12 cells. Febs J. 2009; 276:3269-76. [PubMed: 19438724]

63. Ventura A, Young AG, Winslow MM, Lintault L, Meissner A, Erkeland SJ, et al. Targeted deletion reveals essential and overlapping functions of the miR-17 through 92 family of miRNA clusters. Cell. 2008; 132:875-86. [PubMed: 18329372] 
64. Dolken L, Malterer G, Erhard F, Kothe S, Friedel CC, Suffert G, et al. Systematic analysis of viral and cellular microRNA targets in cells latently infected with human gamma-herpesviruses by RISC immunoprecipitation assay. Cell Host Microbe. 2010; 7:324-34. [PubMed: 20413099]

65. Bellot G, Cartron PF, Er E, Oliver L, Juin P, Armstrong LC, et al. TOM22, a core component of the mitochondria outer membrane protein translocation pore, is a mitochondrial receptor for the proapoptotic protein Bax. Cell Death Differ. 2007; 14:785-94. [PubMed: 17096026]

66. Iizasa H, Wulff BE, Alla NR, Maragkakis M, Megraw M, Hatzigeorgiou A, et al. Editing of Epstein-Barr virus-encoded BART6 microRNAs controls their dicer targeting and consequently affects viral latency. J Biol Chem. 2010; 285:33358-70. [PubMed: 20716523]

67. Nachmani D, Stern-Ginossar N, Sarid R, Mandelboim O. Diverse herpesvirus microRNAs target the stress-induced immune ligand MICB to escape recognition by natural killer cells. Cell Host Microbe. 2009; 5:376-85. [PubMed: 19380116]

68. Chen X, Ba Y, Ma L, Cai X, Yin Y, Wang K, et al. Characterization of microRNAs in serum: a novel class of biomarkers for diagnosis of cancer and other diseases. Cell Res. 2008; 18:997-1006. [PubMed: 18766170]

69. Lawrie CH, Gal S, Dunlop HM, Pushkaran B, Liggins AP, Pulford K, et al. Detection of elevated levels of tumour-associated microRNAs in serum of patients with diffuse large B-cell lymphoma. Br J Haematol. 2008; 141:672-5. [PubMed: 18318758]

70. Mitchell PS, Parkin RK, Kroh EM, Fritz BR, Wyman SK, Pogosova-Agadjanyan EL, et al. Circulating microRNAs as stable blood-based markers for cancer detection. Proc Natl Acad Sci U S A. 2008; 105:10513-8. [PubMed: 18663219]

71. Gourzones C, Gelin A, Bombik I, Klibi J, Verillaud B, Guigay J, et al. Extra-cellular release and blood diffusion of BART viral micro-RNAs produced by EBV-infected nasopharyngeal carcinoma cells. Virol J. 2010; 7:271. [PubMed: 20950422]

72. Brase JC, Wuttig D, Kuner R, Sultmann H. Serum microRNAs as non-invasive biomarkers for cancer. Mol Cancer. 2010; 9:306. [PubMed: 21110877]

73. Valadi H, Ekstrom K, Bossios A, Sjostrand M, Lee JJ, Lotvall JO. Exosome-mediated transfer of mRNAs and microRNAs is a novel mechanism of genetic exchange between cells. Nat Cell Biol. 2007; 9:654-9. [PubMed: 17486113]

74. Meckes DG Jr. Shair KH, Marquitz AR, Kung CP, Edwards RH, Raab-Traub N. Human tumor virus utilizes exosomes for intercellular communication. Proc Natl Acad Sci U S A. 2010; 107:20370-5. [PubMed: 21059916]

75. Pegtel DM, Cosmopoulos K, Thorley-Lawson DA, van Eijndhoven MA, Hopmans ES, Lindenberg JL, et al. Functional delivery of viral miRNAs via exosomes. Proc Natl Acad Sci U S A. 2010; 107:6328-33. [PubMed: 20304794]

76. Xing L, Kieff E. cis-Acting effects on RNA processing and Drosha cleavage prevent Epstein-Barr virus latency III BHRF1 expression. J Virol. 2011; 85:8929-39. [PubMed: 21697496] 


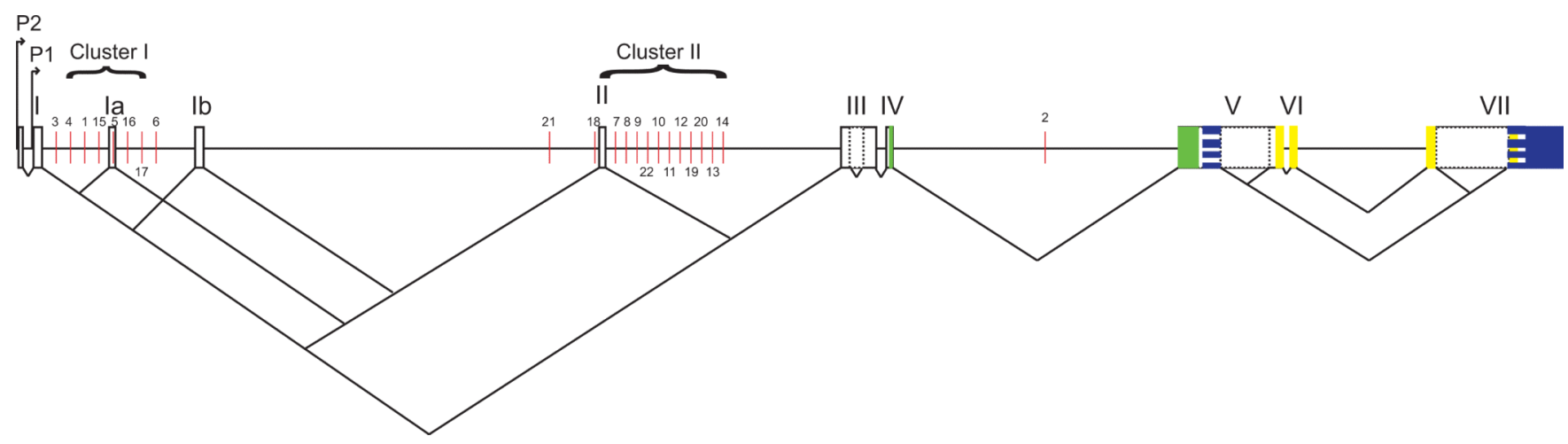

Figure 1. Diagram of the BART transcripts

A diagram of the $22 \mathrm{kD}$ BART locus drawn to scale. The exons are indicated as boxes and are labeled with Roman numerals. The introns are indicated as lines between the boxes. The positions of the potential open reading frames are indicated by color boxes. BARF0 is shaded in blue, with the RK-BARF0 extension indicated by stripes. RPMS1 is indicated by the green box and A73 with yellow. The position of the BART miRNAs are indicated by red lines, and each are numbered according to the accepted nomenclature. The diagonal lines below the transcript indicate the various splicing events that have been observed. 


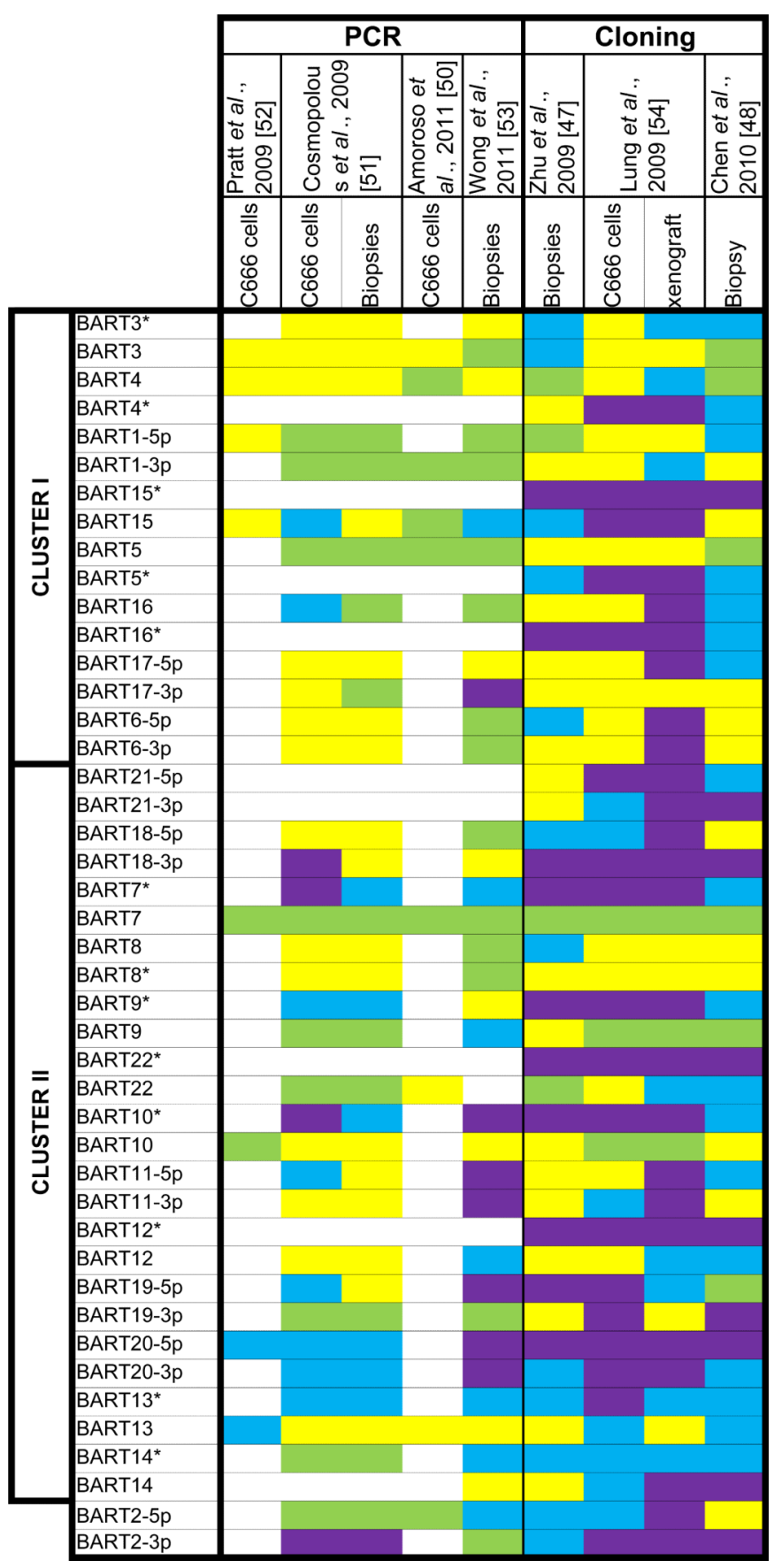

Figure 2. Expression of the BART miRNAs from RT-PCR and small RNA sequencing studies in NPC

A table comparing the available expression data for the BART miRNAs in NPC tumors and the NPC cell line, C666. For each study, the expression levels of each miRNA were broken into four categories, high (green), moderate (yellow), low (blue), or very low (purple). The white boxes on the PCR half of the table indicate a miRNA that wasn't evaluated in that study. The median values of each category differ by an order of magnitude. For the PCR studies the green miRNAs indicate those expressed at approximately 10,000 copies/10 $\mu \mathrm{g}$ RNA, yellow $\sim 1,000$ copies, blue $\sim 100$ copies, and purple $\sim 10$ copies. For the sequencing 
studies, green indicates miRNAs that appear at a frequency of approximately $10 \%$ of the total pool of miRNAs, yellow $\sim 1 \%$, blue $\sim 0.1 \%$, and purple $\sim 0.01 \%$ to undetected. 